\title{
Efficacy of selected treadmill training programme on oxidative stress in adolescents with Down syndrome
}

\author{
N.A. Meguid, ${ }^{1}$ A.M. Eltohamy, ${ }^{2}$ M. Anwar, ${ }^{7}$ A.F. Hashish ${ }^{7}$ and A. Elnahry ${ }^{7}$
}

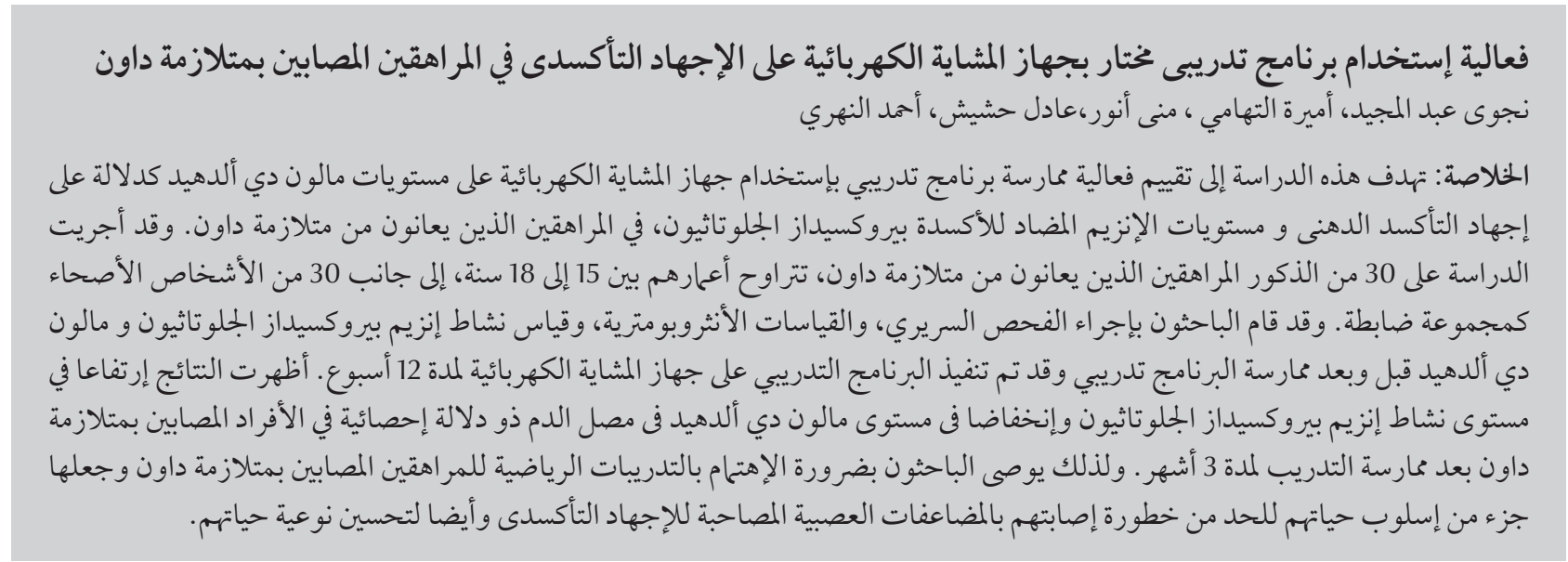

ABSTRACT The aim of this study was to assess the efficacy of an electronic treadmill exercise training programme on malondialdehyde (MDA) as a marker for lipid peroxidation and the antioxidant enzyme glutathione peroxidase (GPx) in adolescents with Down syndrome. The study was carried out on 30 adolescent males with Down syndrome, ranging in age from 15 to 18 years, with 30 healthy subjects as a control group. Clinical examination, anthropometric measurements and determination of GPx activity and MDA before and after exercise were done. A treadmill training programme was performed for 12 weeks. Our data showed a significant increase in GPx activity and decrease in serum level of MDA in Down syndrome individuals after treadmill exercise for 3 months. Exercise promotion for adolescents with Down syndrome requires attention to motivators and facilitators of exercise adherence as it may limit risk of increased neurological consequences associated with oxidative stress and improve quality of life.

Efficacité d'un programme d'exercice sélectionné sur tapis roulant sur le stress oxydatif d'adolescents atteints du Syndrome de Down

RÉSUMÉ L'objectif de la présente étude était d'évaluer l'efficacité d'un programme d'exercice sur tapis roulant électronique sur le malondialdéhyde, en tant que marqueur de la peroxydation lipidique et sur une enzyme antioxydante, le glutathion peroxydase, chez des adolescents atteints du Syndrome de Down. La présente étude a été menée auprès de 30 adolescents de sexe masculin atteints du Syndrome de Down, âgés de 15 à 18 ans, et de 30 sujets en bonne santé dans un groupe témoin. On a procédé à un examen clinique, à des mesures anthropométriques et à la détermination de l'activité du glutathion peroxydase ainsi que du malondialdéhyde avant et après l'exercice. Un programme d'exercice sur tapis roulant a été suivi pendant 12 semaines. Nos données ont révélé une augmentation significative de l'activité du glutathion peroxydase et une diminution de la concentration sérique du malondialdéhyde chez les personnes atteintes du Syndrome de Down après un programme d'exercice sur tapis roulant pendant trois mois. La promotion de l'exercice physique auprès des adolescents atteints du Syndrome de Down implique qu'une attention particulière soit accordée aux facteurs de motivation et d'incitation à la pratique régulière d'une activité physique. En effet, une activité physique régulière permetterait de limiter le risque de conséquences neurologiques accrues associées au stress oxydatif et d'améliorer la qualité de vie.

'Department of Research on Children with Special Needs, National Research Center, Cairo, Egypt (Correspondence to N.A. Meguid: meguidna@ yahoo.com).

${ }^{2}$ Department of Physical Therapy for Disturbances of Growth and Development and its Surgery in Pediatrics, Faculty of Physical Therapy, Cairo University, Cairo, Egypt.

Received: 19/09/12; accepted: 09/12/12 


\section{Introduction}

The increase in life expectancy of the general population has resulted in an increasing number of elderly adults, including adults with Down syndrome who currently have a life expectancy of about 50 years. Individuals with Down syndrome have been described as having high levels of oxidative stress [1]. Research on this topic may be of great interest since oxidative damage has been proposed as a pathogenic mechanism of atherosclerosis, cell ageing, neurodegeneration [2], carcinogenic events and immunological disorders in this population [3].

Oxidative stress is a term used to describe the effect of oxidation in which an abnormal level of reactive oxygen species, such as free radicals (e.g. hydroxyl, superoxide radicals) or non-radical (e.g. lipid peroxide), lead to damage of specific molecules with consequential injury to cells or tissues [4]. An increase in oxidative stress in individuals with Down syndrome may cause adverse effects in cell membranes through the oxidation of polyunsaturated fatty acids [5]. Decreased glutathione peroxidase (GPx) has been observed in the brain of those with Down syndrome, which may be the cause of neurotransmitter impairment [6]. GPx plays an important role in preventing peroxide accumulation in cells and in subsequently preventing lipid peroxide formation; it may have an important role in protection from progression of neurobiological abnormalities within cells of individuals with Down syndrome [5].

The aim of this study was to determine the efficacy of a treadmill training programme on oxidative stress in adolescents with Down syndrome.

\section{Methods}

\section{Subjects}

Thirty clinically healthy subjects, age and sex matched to the Down syndrome group, were included in the study; they did not receive any programme of training. Thirty males with Down syndrome ranging in age from 15 to 18 years were selected from the Children with Special Needs outpatient clinic of the National Research Centre, Cairo. All patients were trainable and could walk freely. They were able to understand and follow verbal commands and instructions. The study and the informed consent procedures were approved by the Ethics Review Committee of the National Research Centre.

\section{Investigations}

Clinical investigations included history-taking and clinical examination. Anthropometric measurements included weight, height and body mass index (BMI), calculated as weight $(\mathrm{kg}) /$ height $(\mathrm{m})^{2}$.

For biochemical investigations, blood was withdrawn and collected in heparinized tubes. An enzyme-linked immunosorbent assay (ELISA) kit provided by BioVender Laboratories Ltd, Germany was used for determination of GPx activity. Determination of malondialdehyde (MDA) as a marker of lipid peroxidation was carried out using quantitative colorimetric microplates. These biochemical parameters were determined for the control group, and before starting and at the end of the training programme for the Down syndrome group.

\section{Intervention}

Down syndrome individuals exercised on an electronic treadmill for 12 weeks (three sessions per week) in the Physical Therapy College, Cairo University. The duration of each session was increased gradually from 10 minutes at the start of the training programme to 40 minutes at the end of the programme. The sessions were divided into warming up, active phase training and cooling down periods.

The treadmill training programme was as follows:

- Week 1: speed 1.5-2 mph, incline $3 \%$, time $10 \mathrm{~min}$.
- Week 2: speed 2-2.5 mph, incline $5 \%$, time $16 \mathrm{~min}$.

- Week 3: speed 2.5-3 mph, incline $7 \%$, time $22 \mathrm{~min}$.

- Week 4: speed 3-3.5 mph, incline $9 \%$, time $25 \mathrm{~min}$.

- Weeks 5-12: speed 4-5 mph, incline $14 \%$, time 40 min.

\section{Results}

The results of this study revealed the following data.

\section{Before training}

A statistically significant difference was noted between both groups as regards weight, height and BMI. There was a significant decrease in GPx level and a significant increase in MDA levels in the Down syndrome group compared with the control group (Table 1).

Significant negative correlation was shown between GPx level and BMI (Figure 1) and a significant positive correlation was shown between MDA level and BMI (Figure 2) in the Down syndrome patients before the exercise training programme $(r=-0.0522, P=0.001$ and $r=0.290, P=0.012$, respectively). Significant and negative correlation was shown between MDA and GPx levels in Down syndrome individuals, with $r=$ 0.269 and $P=0.019$ (Figure 3).

\section{After training}

There was no significance difference regarding weight, height and BMI in the Down syndrome group before and after exercise. However, there was a significance increase in GPx level and a significance decrease in MDA level in the Down syndrome group before and after exercise (Table 2). Results showed a significant and negative correlation between GPx level and BMI $(r=-0.434$ and $P=0.003$; Figure 4$)$, a significant and positive correlation between MDA and BMI ( $r=0.318$ and $P=0.006$; Figure 5) and a significant and negative correlation between MDA 


\begin{tabular}{|c|c|c|c|c|}
\hline \multirow[t]{2}{*}{ Item } & Control group $(n=30)$ & Down syndrome group $(n=30)$ & $t$-value & $P$-value ${ }^{\text {a }}$ \\
\hline & Mean (SD) & Mean (SD) & & \\
\hline Age (years) & $16.73(1.01)$ & $16.56(1.07)$ & 0.61 & 0.53 \\
\hline Weight (kg) & $66.6(6.59)$ & $69.93(4.60)$ & 2.27 & 0.01 \\
\hline Height (m) & $1.64(0.05)$ & $1.58(0.04)$ & 3.98 & 0.00 \\
\hline $\mathrm{BMI}\left(\mathrm{kg} / \mathrm{m}^{2}\right)$ & $24.03(2.17)$ & $27.72(1.92)$ & 7.09 & 0.00 \\
\hline GPx (U/g Hb) & $23.89(5.30)$ & $18.39(5.29)$ & 5.41 & 0.00 \\
\hline $\operatorname{MDA}(\mu \mathrm{mol} / \mathrm{L})$ & $0.87(0.28)$ & $1.52(0.76)$ & 7.68 & 0.00 \\
\hline
\end{tabular}

${ }^{a} P>0.05$ non-significant; $P \leq 0.05$ significant.

$B M I=$ body mass index $; G X=$ glutathione peroxidase $; M D A=$ malondialdehyde.

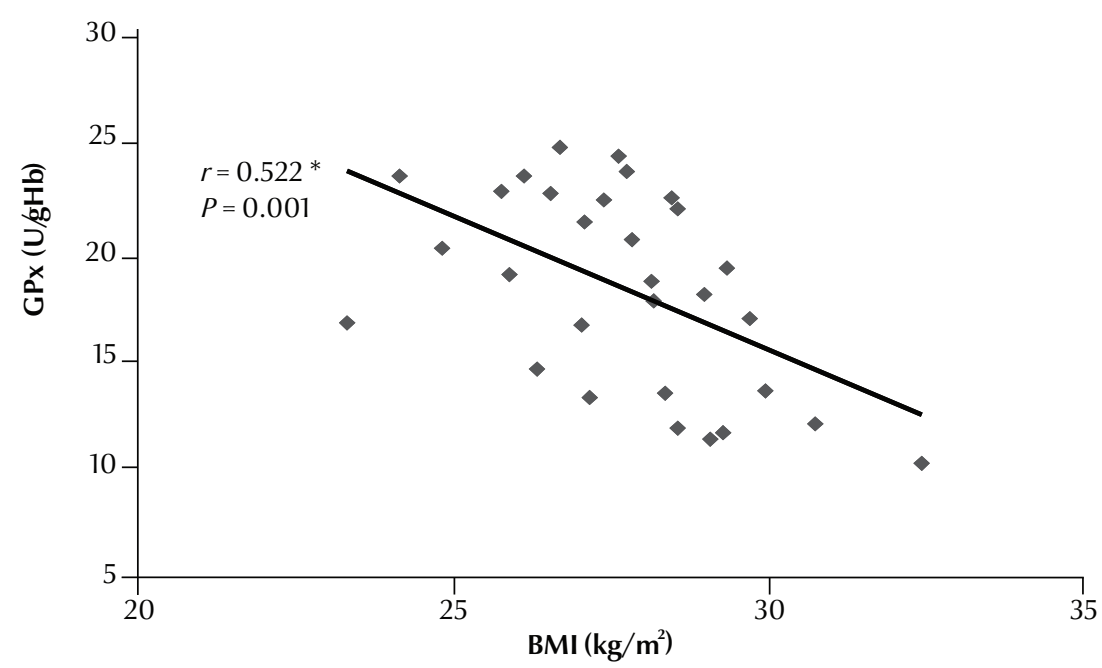

Figure 1 Correlation between glutathione peroxidase (GPx) and body mass index $(\mathrm{BMI})$ before exercise $(P<0.05$ : significant; $r=$ correlation coefficient $)$

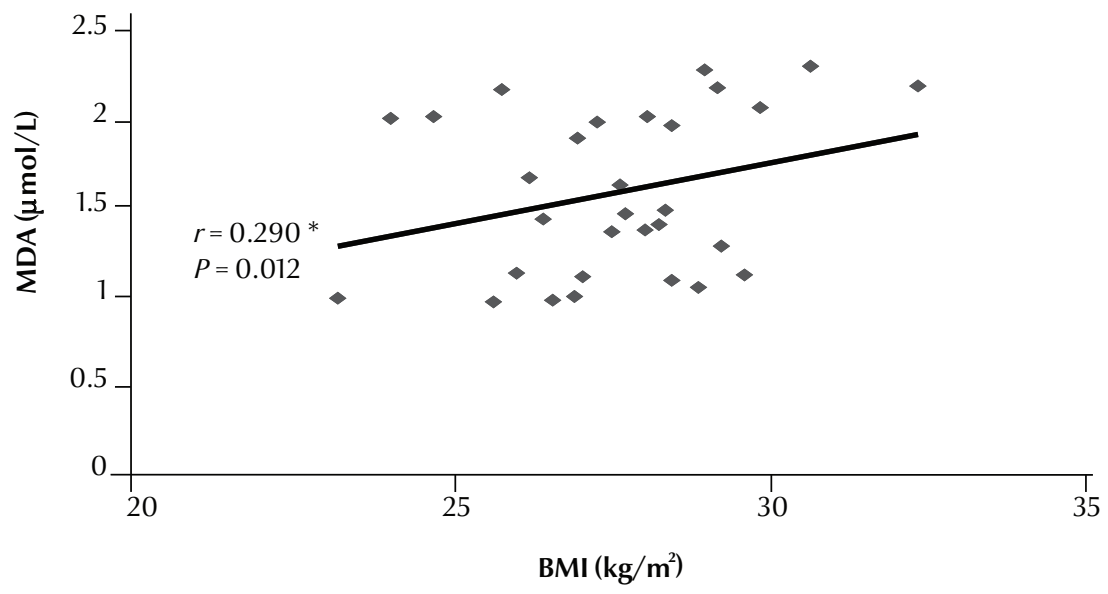

Figure 2 Correlation between malondialdehyde (MDA) and body mass index (BMI) before exercise $(\boldsymbol{P}<0.05$ : significant; $r=$ correlation coefficient $)$ and GPx levels $(r=0.340$ and $P=0.003$

(Figure 6).

\section{Discussion}

Although the general physiology of exercise has been a very active area of research during the past 40 years, the neurobiology of exercise has been virtually absent from public health discourse [7]. Emerging evidence suggests that physical activity may confer health protective benefits for several neurological diseases such as Alzheimer's dementia [8].

Regular physical activity or exercise has other important benefits in addition to weight loss, including lowering atherogenic lipid molecules, improving glucose intolerance, and increasing flexibility and motor coordination [9]. Such benefits are in addition to psychological effects, including improvement of self-esteem, and social interaction and confidence.

This study was conducted to assess the effect of using an electronic treadmill exercise programme on some oxidative stress biomarkers in adolescents with Down syndrome.

The majority of studies that have evaluated anthropometric indices of Down syndrome individuals with mental retardation have reported that the prevalence for obesity in this population 


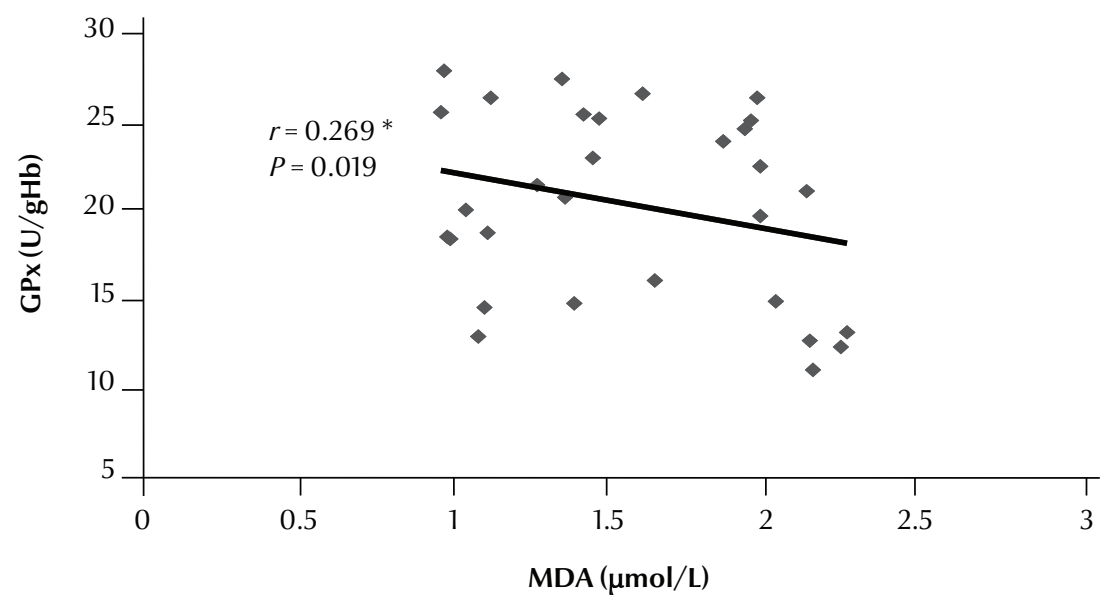

Figure 3 Correlation between glutathione peroxidase (GPx) and malondialdehyde (MDA) before exercise $(P<0.05$ : significant; $r=$ correlation coefficient)

is high, and may be twice as high as in their peers without mental retardation [10]. This may be due to an increased prevalence of thyroid disease, particularly subclinical hypothyroidism [11]. Andriolo et al. [12] theorized that a lower resting metabolic rate was a cause of increased rates of obesity in individuals with Down syndrome. In the present study, mean weight and BMI of the Down syndrome group was significantly higher than the control group $(P>0.01$ and $P>0.00$, respectively $)$. However, there was no significant decrease in mean weight and BMI in Down syndrome individuals after the 12-week treadmill training programme compared with that at the beginning of the exercise programme. Similar results were observed by Aguiar et al. [13] who reported no significant weight changes and a slight decrease in BMI in Down syndrome adolescents at the end of a supervised 16-week judo-training programme of controlled intensity comparison with the beginning of the programme.

Regarding GPx and BMI, significant and negative correlation was found in Down syndrome individuals before and after the exercise training programme ( $P=0.001$ and 0.003 , respectively). Similarly, Roussel et al. [14] reported an inverse relationship between the erythrocyte cytoprotective enzyme GPx and BMI in healthy obese and overweight with impaired fasting blood glucose. On the other hand, Ordonez and Rosety-Rodriguez [15] reported that BMI was not significantly correlated to GPx in a study dealing with GPx activity and anthropometrical parameters in adolescents with Down syndrome. In the present study BMI was also significantly correlated with MDA level. This result is in agreement with Mohn et al. [16], who demonstrated association between $\mathrm{BMI}$ and MDA in obese prepubertal children.

In the present study, GPx activity was significantly lower in the Down syndrome group compared with the control group $(P<0.00)$. Similar results were reported by Muchova et al. [17] who demonstrated a significant lowering of reduced glutathione concentration in Down syndrome individuals that led to a decrease in GPx activity.

Our results revealed an increase in GPx activity after a 12-week treadmill training programme, compared with its activity before exercise $(P<0.01)$ This agrees with Ordoñez et al. [18] who found that a 12-week training programme increased erythrocyte antioxidant enzyme activities such as GPx in adolescents with Down syndrome. Similar results have been reported regarding the effect of regular exercise training, for example 12 weeks of moderate intensity aerobic exercise performed 3 days a week on antioxidant defence mechanisms resulted in an up-regulation in antioxidant enzymes, evident by an increase in the activity of superoxide dismutase, GPx and catalase [19].

Mechanisms involved in the regulation of some antioxidant enzymes through exercise have been described.

\begin{tabular}{|c|c|c|c|c|}
\hline \multirow[t]{2}{*}{ Item } & $\begin{array}{c}\text { Downs syndrome before } \\
\text { exercise }(n=30)\end{array}$ & $\begin{array}{l}\text { Down syndrome after } \\
\text { exercise }(n=30)\end{array}$ & $t$-value & $P$-value ${ }^{a}$ \\
\hline & Mean (SD) & Mean (SD) & & \\
\hline Weight (kg) & $69.93(4.6)$ & $68.2(4.3)$ & 0.64 & 0.26 \\
\hline Height (m) & $1.58(0.04)$ & $1.58(0.04)$ & 0.001 & 0.50 \\
\hline BMI $\left(\mathrm{kg} / \mathrm{m}^{2}\right)$ & 27.72 (1.92) & 27.40 (1.8) & 0.59 & 0.27 \\
\hline GPx (U/gHb) & 18.39 (5.29) & $20.92(5.07)$ & 2.30 & 0.01 \\
\hline $\mathrm{MDA}(\mu \mathrm{mol} / \mathrm{L})$ & $1.52(0.76)$ & $1.13(0.52)$ & 4.10 & 0.00 \\
\hline
\end{tabular}

${ }^{a} P>0.05$ non-significant; $P \leq 0.05$ significant.

$B M I=$ body mass index $; G P X=$ glutathione peroxidase $; M D A=$ malondialdehyde . 


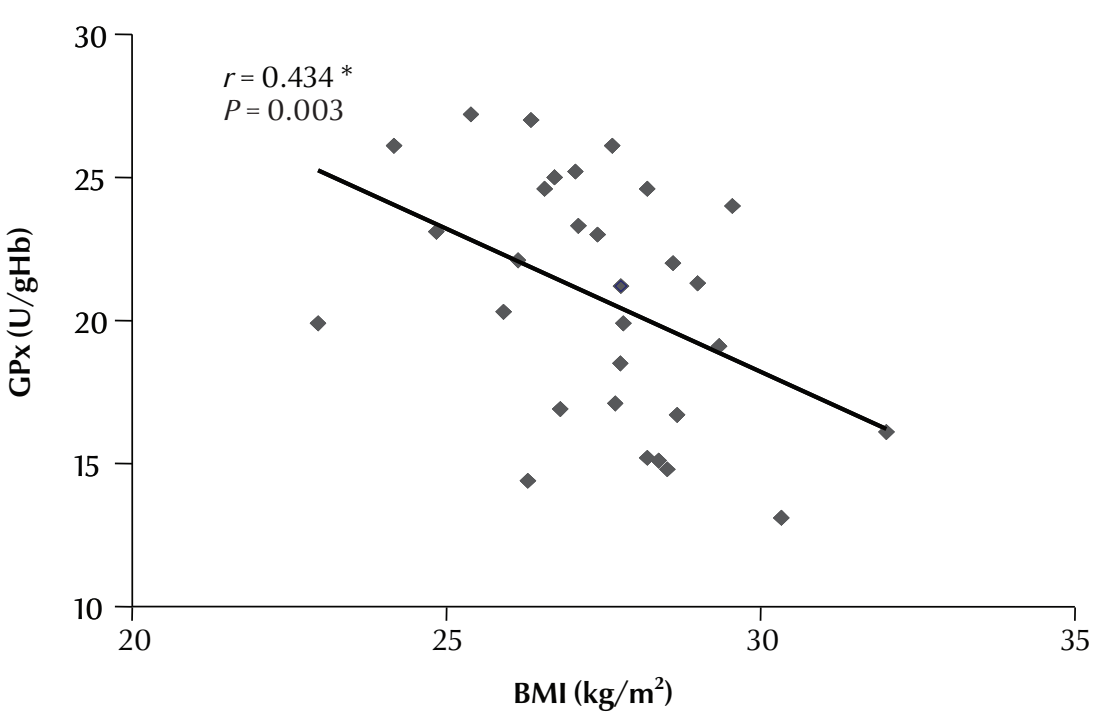

Figure 4 Correlation between glutathione peroxidase (GPx) and body mass index (BMI) after exercise $(\boldsymbol{P}<\mathbf{0 . 0 5}$ : significant; $\boldsymbol{r}=$ correlation coefficient)

Carvalho et al. [20] reported that an increase in the plasma activities of both glutathione reductase and GPx may be due to up-regulation of antioxidant enzyme mRNA, protein concentrations and activity during and after the exercise closely related to redox changes, due to the role of reactive oxygen and nitrogen species as important signalling molecules. The chronic increase in reactive oxygen and nitrogen species production during multicomponent training

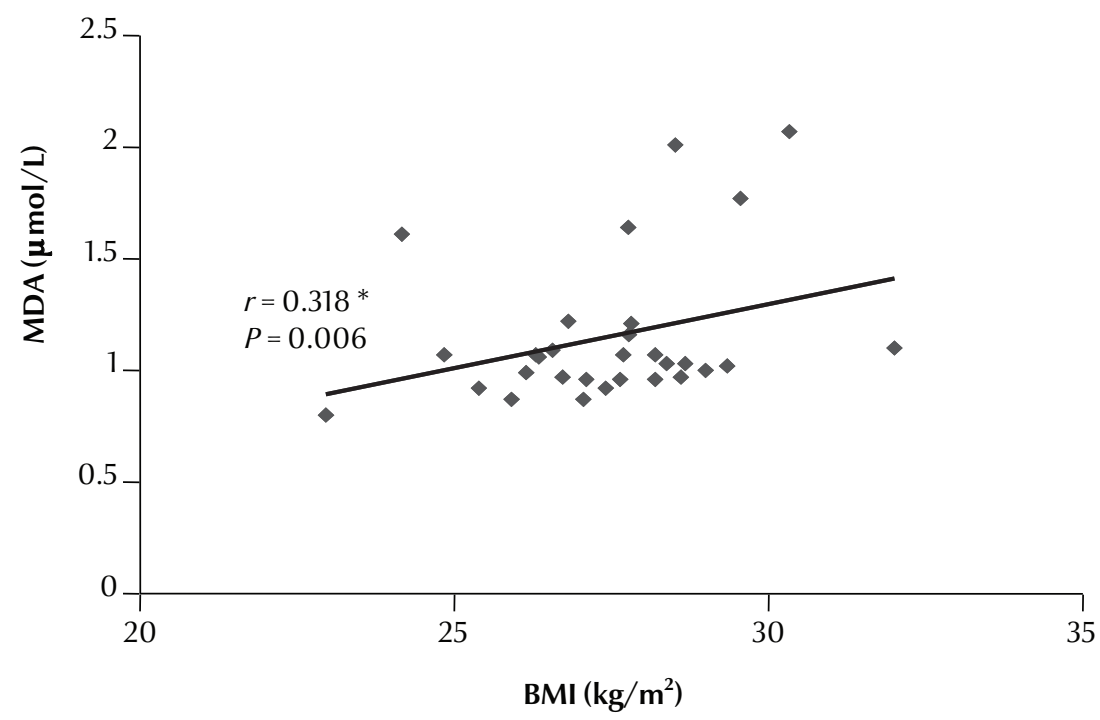

Figure 5 Correlation between malondialdehyde (MDA) and body mass index (BMI) after exercise $(P<0.05$ : significant; $r=$ correlation coefficient) stress in vivo. Increased lipid peroxidation products in individuals with Down syndrome have been reported [21]. Recent studies have demonstrated higher levels of MDA and thiobarbituric acid reactive substances in Alzheimer disease [22]. In the present study, serum MDA level was significantly higher in the Down syndrome group compared with the control group $(P>0.001)$ denoting an increased rate of oxidative damage in individuals with Down syndrome.

Our data showed that treadmill regular exercise for 3 months significantly reduced serum MDA levels in the Down syndrome group compared with levels at the beginning of the exercise programme $(P<0.00)$. Similar results have been reported by Ordonez and Rosety-Rodriguez [15] who observed that a 12-week exercise programme significantly reduced lipid peroxidation in terms of plasmatic MDA content in male adolescents with Down syndrome. This finding may be due to improved serum lipid profiles in adolescents with Down syndrome, as high-density lipoprotein (HDL) cholesterol increased whereas low-density lipoprotein (LDL) cholesterol decreased. This may contribute, at least in part, to improving lipoperoxidation in exercised individuals, since LDL oxidation can be inhibited by HDL through its oxidizable components or associated enzymes such as paraoxonase and platelet-activating factor acetylhydrolase [23].

Zambrano et al. [24] also reported a decrease in salivary lipid hydroperoxides in persons with Down syndrome after aerobic exercise and suggested that aerobic exercise could be considered as a way to reduce oxidative stress in those persons. Previous studies addressing the role of physical exercise in oxidative stress and antioxidant status in people with Down syndrome have shown conflicting results. The extensive literature indicates that moderate exercise similar to that used in the present study exerts low stress without oxidative damage 


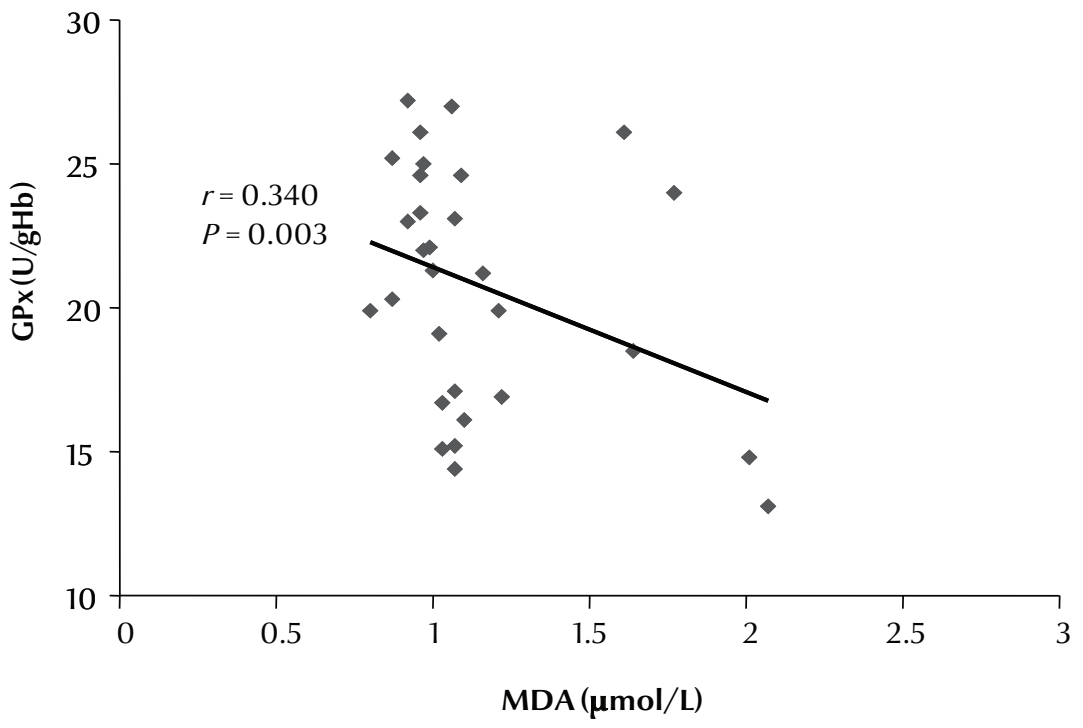

Figure 6 Correlation between glutathione peroxidase (GPx) and malondialdehyde (MDA) after exercise $(\boldsymbol{P}<0.05$ : significant; $\boldsymbol{r}=$ correlation coefficient)

consequences in non-Down syndrome subjects [25].

Interestingly, Aguiar et al. [13] showed that blood markers of oxidative damage to lipids (thiobarbituric acid reactive substances and lipid peroxides) and proteins (carbonyls) increased that have demonstrated increased GPX activity. These inconsistent data may be explained by differences in the age of the subjects [23.3 (SD 2.1) years versus 16 (SD 1.1) years] and the duration of the training programmes (16 versus 12 weeks).

\section{Conclusion}

A regular 12-week treadmill exercise programme is highly recommended for adolescents with Down syndrome as it improves the level of the antioxidant enzyme GPx and decreases the level of the lipid peroxidation marker MDA. Exercise at this intensity may decrease risk factors for diseases associated with oxidative stress in this population. Further studies are recommended to detect the effect of treadmill training on oxidative stress in different age groups of Down syndrome individuals.

Funding: National Research Centre, Cairo, Egypt.

Competing interests: None declared.

\section{References}

1. Sulthana SM etal. Levels of non enzymatic antioxidants in Down syndrome. Indian Journal of Pediatrics, 2012, 79:1473-1476.

2. Lockrow JP et al. Age-related neurodegeneration and memory loss in down syndrome. Current Gerontology and Geriatrics Research, 2012, 2012:463909.

3. Gemen EF et al. Increased circulating apoptotic lymphocytes in children with Down syndrome. Pediatric Blood \& Cancer, 2012, 59:1310-1312.

4. Mazza M et al. Omega-3 fatty acids and antioxidants in neurological and psychiatric diseases: an overview. Progress in Neuro-Psychopharmacology \& Biological Psychiatry, 2007, 31:12-26.

5. Garcez ME et al. Oxidative stress and 122 hematologic and biochemical parameters in individuals with Down syndrome. Mayo Clinic Proceedings, 2005, 80:1607-1611.

6. Keiichi Ishihara et al. Increased lipid peroxidation in Down's syndrome mouse models. Journal of Neurochemistry, 2009, 110:1965-1976.

7. Booth FW et al. Waging war on physical inactivity: using modern molecular ammunition against an ancient enemy. Journal of Applied Physiology, 2002, 93:3-30.

8. Cotman CW et al. Exercise: a behavioral intervention to enhance brain health and plasticity. Trends in Neurosciences, 2002, 25:295-301.

9. Elentz CA et al. Effects of a mount of exercises on body weight and measures of central obesity. Archives of Internal Medicine, 2009, 164:31-35.
10. Baynard T et al. Heart rate variability at rest and during exercise in persons with Down syndrome. Archives of Physical Medicine and Rehabilitation, 2004, 85:1285-1290.

11. Mıhçı E et al. Evaluation of congenital heart diseases and thyroid abnormalities in children with Down syndrome. Anadolu Kardiyoloji Dergisi, 2010, 10:440-445.

12. Andriolo RB et al. Aerobic exercise training programs for improving physical and psychosocial health in adults with Down syndrome. Cochrane Database of Systematic Reviews, 2010, 5:CD005176.

13. Aguiar AS Jr et al. The exercise redox paradigm in the Down's syndrome: improvements in motor function and increases in blood oxidative status in young adults. Journal of Neural Transmission, 2008, 115:1643-1650.

14. Roussel AM et al. Antioxidant effects of a cinnamon extract in people with impaired fasting glucose that are overweight or obese. Journal of the American College of Nutrition, 2009, 28:16-21.

15. Ordonez FJ, Rosety-Rodriguez M. Correlation between glutathione peroxidase activity and anthropometrical parameters in adolescents with Down syndrome. Research in Developmental Disabilities, 2007, 2:105-108.

16. Mohn A et al. Increased oxidative stress in prepubertal severely obese children: effect of a dietary restriction-weight loss program. Journal of Clinical Endocrinology and Metabolism, 2005, 90:2653-2658. 
17. Muchova J et al. Influence of age on activities of antioxidant enzymes and lipid peroxidation products in erythrocytes and neutrophils of Down syndrome patients. Free Radical Biology \& Medicine, 2001, 31:499-508.

18. Ordoñez FJ et al. Regular exercise did not modify significantly superoxide dismutase activity in adolescents with Down's syndrome. British Journal of Sports Medicine, 2006, 40:717-718.

19. Linke A et al. Antioxidative effects of exercise training in patients with chronic heart failure: increase in radical scavenger enzyme activity in skeletal muscle. Circulation, 2005, 111:1763-1770.

20. Carvalho J et al. Multicomponent exercise program improves blood lipid profile and antioxidant capacity in older women. Archives of Gerontology and Geriatrics, 2010, 51:1-5.
21. Casado A et al. Lipid peroxidation in Down syndrome caused by regular trisomy 21, trisomy 21 by Robertsonian translocation and mosaic trisomy 21. Clinical Chemistry and Laboratory Medicine, 2007, 45:59-62

22. Gustaw-Rothenberg $\mathrm{K}$ et al. Lipids' peroxidation markers in Alzheimer's disease and vascular dementia. Geriatrics \& Gerontology International, 2010, 10:161-166.

23. Brites $\mathrm{F}$ et al. HDL capacity to inhibit LDL oxidation in welltrained triathletes. Life Sciences, 2006, 78:3074-3081.

24. Zambrano JC et al. Aerobic exercise reduced oxidative stress in saliva of persons with Down syndrome. Research in Sports Medicine, 2009, 17:195-203.

25. Apor P et al. Physical exercise, oxidative stress and damage. Orvosi Hetilap, 2006, 147:1025-1031. 